\title{
Patterns in mortality among people with severe mental disorders across birth cohorts: a register-based study of Denmark and Finland in 1982-2006
}

Mika Gissler ${ }^{1,2^{*}}$, Thomas Munk Laursen ${ }^{1,3}$, Urban Ösby $^{4,5}$, Merete Nordentoft ${ }^{6}$ and Kristian Wahlbeck ${ }^{1,2}$

\begin{abstract}
Background: Mortality among patients with mental disorders is higher than in general population. By using national longitudinal registers, we studied mortality changes and excess mortality across birth cohorts among people with severe mental disorders in Denmark and Finland.

Methods: A cohort of all patients admitted with a psychiatric disorder in 1982-2006 was followed until death or 31 December 2006. Total mortality rates were calculated for five-year birth cohorts from 1918-1922 until 1983-1987 for people with mental disorder and compared to the mortality rates among the general population.

Results: Mortality among patients with severe mental disorders declined, but patients with mental disorders had a higher mortality than general population in all birth cohorts in both countries. We observed two exceptions to the declining mortality differences. First, the excess mortality stagnated among Finnish men born in 1963-1987, and remained five to six times higher than at ages 15-24 years in general. Second, the excess mortality stagnated for Danish and Finnish women born in 1933-1957, and remained six-fold in Denmark and Finland at ages 45-49 years and seven-fold in Denmark at ages 40-44 years compared to general population.

Conclusions: The mortality gap between people with severe mental disorders and the general population decreased, but there was no improvement for young Finnish men with mental disorders. The Finnish recession in the early 1990s may have adversely affected mortality of adolescent and young adult men with mental disorders. Among women born 1933-1957, the lack of improvement may reflect adverse effects of the era of extensive hospitalisation of people with mental disorders in both countries.
\end{abstract}

Keywords: Birth cohort, Mental disorder, Mortality, Psychiatric care, Register study

\section{Background}

Life span has increased during the last decades in Europe. Since 1982, the life expectancy at birth increased by four years in Denmark and by six years in Finland [1]. Our previous studies have shown that the life expectancy among people with severe mental disorders also has increased from the 1980s in Denmark and Finland $[2,3]$. It is not clear whether this progress has

\footnotetext{
* Correspondence: mika.gissler@nhv.se

${ }^{1}$ Nordic Research Academy in Mental Health, Nordic School of Public Health, Gothenburg, Sweden

${ }^{2}$ THL National Institute for Health and Welfare, Helsinki, Finland

Full list of author information is available at the end of the article
}

been gradual across generations, or whether there are some birth cohorts who divert from the general picture. Even though the general trend has been positive, men with severe mental disorders still live 20 years less and women 15 years less than general population in the Nordic countries.

The excess mortality among people with severe mental disorders is not only caused by an increased risk for suicides and unintentional injuries, but also from an increased risk for mortality from diseases and medical conditions, such as diseases of the circulatory system, cancer and diabetes [4-6]. The literature suggests that this can partly be explained by low socioeconomic status

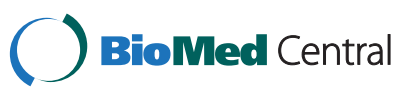


$[7,8]$, unhealthy lifestyle habits $[9,10]$ and lack of access to health care with good quality $[5,11]$. Neither can the metabolic side effects of psychiatric medication in form of hyperglycemia and diabetes, weight gain, and lipid disturbances be excluded.

Both Denmark and Finland have undergone the major shift from an emphasis on psychiatric hospitalisations to integrated community-based mental health services. Between 1982 and 2006, the number of hospital beds in psychiatric hospitals per 100000 population decreased from 171 to 63 in Denmark (-63\%) and from 390 to 92 in Finland $(-76 \%)$ [1]. The reduction reflects shorter treatment periods, improved primary health care based services and housing services (in Finland) and community mental health services (in Denmark), and the transfer of long-term inpatients in other institutions.

There are good possibilities for population-based studies on mortality among psychiatric patients in the Nordic countries, since the entire population is covered in the comprehensive nation-wide registers on general population, inpatient care and causes of death [6]. Mortality patterns are linked to macroeconomics, and increase in unemployment has been linked to higher suicide and alcohol-related mortality [12]. Economic recessions and depressions have been linked to increased risk of depression and anxiety as well as increased violent behaviour and excess use of alcohol and drugs, which have been hypothesised to have their origin in work-related stress and difficulties in family economy [13]. Excluding suicides, however, no data exists on the links between macroeconomics and mortality in the vulnerable group of people with severe mental disorders.

Denmark and Finland are Nordic countries with a similar culture, societal structure and welfare system. In spite of the social and cultural similarities, they differ in macroeconomic trends due to differing trade and industry. Denmark had a slower economic growth than other Nordic countries in the 1970s (Figure 1), and the country faced a recession 1980s with unemployment rates between $8 \%$ and $10 \%$. The unemployment rose also in the beginning of the 1990 s up to $12 \%$, but cannot be compared to the Finnish rates in the early 1990s. Finland experienced then a sudden and severe economic recession with a five-fold increase in unemployment and a decrease of more than $10 \%$ in the GDP, which led to cuts in public services. The GDP remained below the level of 1990 for five years until 1995 (Figure 1).

Our aim was to compare different birth cohorts to investigate if the development in relative mortality among people with mental disorders in birth cohorts at risk were similar in the two study countries Denmark and Finland, and especially whether major macro-economic cycles had an impact on these trends. A specific question was whether stagnating or declining economy affected the

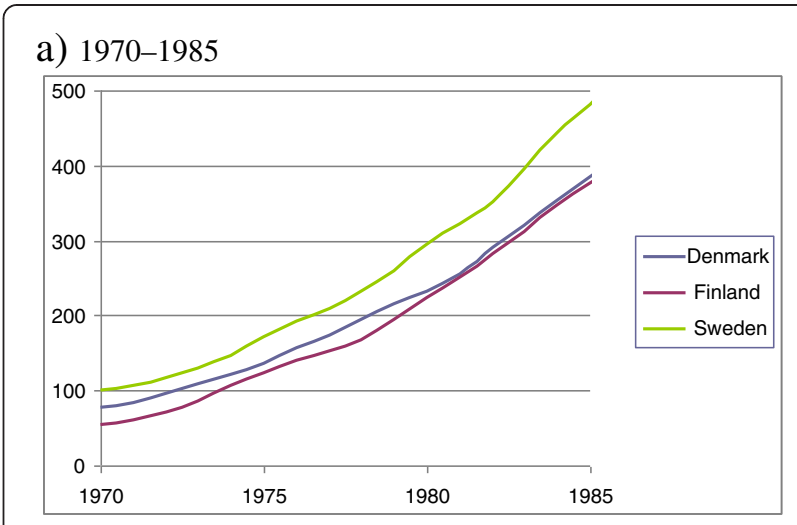

b) $1986-2006$

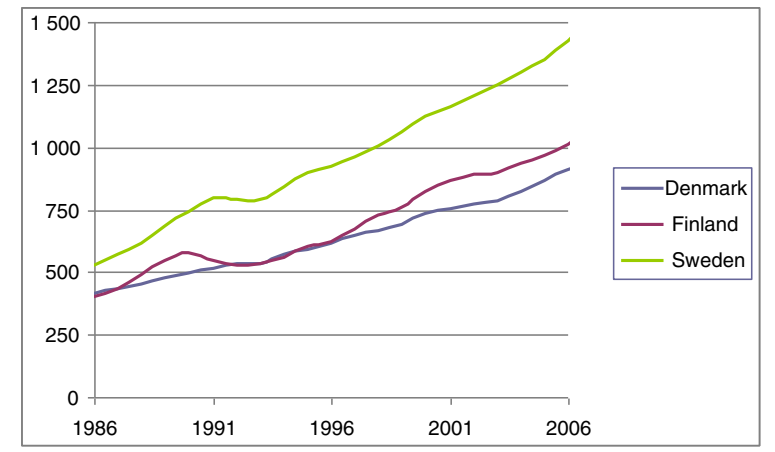

Figure 1 Gross Domestic Product (GDP) in Denmark, Finland and Sweden in a) 1970-1985 and b) 1986-2006. The GDP in Sweden in 1970 (22 772 Swedish Crowns, 4402 US Dollars) is the reference point $(1970=100)$.

mortality among people with severe mental disorders leading to hospitalisation. Any significant differences may be caused by differences how the contemporary societal changes have affected cultural generations, i.e. cohorts of people who were born in the same year range and share similar socio-cultural experience.

\section{Methods}

\section{Case definition}

Cases of severe mental disorders included were identified from discharge diagnoses recorded in the nationwide hospital discharge registers. Both countries use the International Classification of Diseases (ICD), established by the World Health Organization (WHO), for definition and classification of psychiatric and physical diseases in their hospital discharge registers. We used the primary diagnoses given in ICD-8, ICD-9 or ICD-10, recorded for each hospitalisation to define our study population with diagnosed mental disorder. The diagnoses given in ICD-8 and ICD-9 were transformed to ICD-10 diagnoses.

All patients admitted at least once during the period 1 January 1982 and 31 December 2006 with a primary diagnosis of mental disorder (ICD-10: F10-F69) were 
Table 1 The number of follow-up years and deaths by study period, birth cohort and sex in Denmark and Finland

\begin{tabular}{|c|c|c|c|c|c|c|c|c|c|c|c|c|}
\hline & Men & & & & & & Women & & & & & \\
\hline & $1982-86$ & $1987-91$ & $1992-96$ & 1997-01 & $2002-06$ & Total & $1982-86$ & $1987-91$ & $1992-96$ & 1997-01 & 2002-06 & Total \\
\hline \multicolumn{13}{|l|}{ Finland } \\
\hline \multicolumn{13}{|c|}{ Follow-up years } \\
\hline Total & 177301 & 276855 & 493517 & 630559 & 733859 & 2312091 & 115501 & 181663 & 330736 & 447783 & 559779 & 1635462 \\
\hline 1918-22 & 7273 & 8214 & 10255 & 8614 & 5773 & 40129 & 8885 & 11898 & 18584 & 20436 & 18710 & 78513 \\
\hline 1923-27 & 11723 & 13625 & 18069 & 16609 & 13342 & 73368 & 10518 & 14379 & 22582 & 26055 & 26876 & 100410 \\
\hline 1928-32 & 14935 & 19009 & 26821 & 26314 & 23159 & 110238 & 11832 & 16302 & 25689 & 29873 & 32106 & 115802 \\
\hline 1933-37 & 15997 & 21384 & 32702 & 34651 & 33223 & 137957 & 11324 & 17068 & 27671 & 31371 & 33571 & 121005 \\
\hline $1938-42$ & 18685 & 26567 & 42663 & 47591 & 47406 & 182912 & 12021 & 18135 & 31437 & 38014 & 41441 & 141048 \\
\hline $1943-47$ & 24691 & 35961 & 60102 & 70736 & 74320 & 265810 & 15123 & 22867 & 40130 & 51227 & 58160 & 187507 \\
\hline 1948-52 & 27652 & 41733 & 71882 & 86822 & 94882 & 322971 & 16335 & 24960 & 44048 & 57181 & 68249 & 210773 \\
\hline 1953-57 & 22840 & 35087 & 62030 & 77920 & 88976 & 286853 & 13567 & 21503 & 38915 & 51502 & 62540 & 188027 \\
\hline $1958-62$ & 18598 & 27723 & 50089 & 64249 & 75635 & 236294 & 8694 & 15107 & 29397 & 41345 & 52745 & 147288 \\
\hline $1963-67$ & 13707 & 31620 & 54201 & 67333 & 78129 & 244990 & 5809 & 11821 & 24501 & 35897 & 46752 & 124780 \\
\hline 1968-72 & 1200 & 14906 & 45944 & 58408 & 67868 & 188326 & 1393 & 6380 & 16466 & 26145 & 35879 & 86263 \\
\hline 1973-77 & & 1024 & 17079 & 43817 & 56343 & 118263 & & 1243 & 9021 & 19421 & 29536 & 59221 \\
\hline 1978-82 & & & 1680 & 24704 & 53674 & 80058 & & & 2295 & 14747 & 29229 & 46271 \\
\hline 1983-87 & & & & 2791 & 21129 & 23920 & & & & 4569 & 23985 & 28554 \\
\hline \multicolumn{13}{|l|}{ Deaths } \\
\hline Total & 4266 & 7347 & 12633 & 16289 & 18854 & 59389 & 1584 & 2781 & 5207 & 7797 & 10022 & 27391 \\
\hline 1918-22 & 495 & 722 & 1148 & 1153 & 910 & 4428 & 298 & 588 & 1200 & 1711 & 1862 & 5659 \\
\hline $1923-27$ & 644 & 935 & 1509 & 1657 & 1464 & 6209 & 288 & 481 & 896 & 1398 & 1737 & 4800 \\
\hline 1928-32 & 570 & 984 & 1626 & 1822 & 1947 & 6949 & 216 & 384 & 646 & 929 & 1337 & 3512 \\
\hline 1933-37 & 497 & 811 & 1341 & 1663 & 1880 & 6192 & 159 & 260 & 477 & 740 & 870 & 2506 \\
\hline $1938-42$ & 472 & 794 & 1328 & 1803 & 2029 & 6426 & 144 & 266 & 427 & 630 & 799 & 2266 \\
\hline $1943-47$ & 510 & 891 & 1561 & 2101 & 2633 & 7696 & 155 & 232 & 441 & 648 & 909 & 2385 \\
\hline 1948-52 & 457 & 890 & 1574 & 2158 & 2772 & 7851 & 121 & 240 & 405 & 627 & 842 & 2235 \\
\hline 1953-57 & 328 & 637 & 1068 & 1526 & 1902 & 5461 & 116 & 155 & 308 & 475 & 654 & 1708 \\
\hline $1958-62$ & 201 & 343 & 640 & 984 & 1275 & 3443 & 68 & 82 & 192 & 260 & 397 & 999 \\
\hline $1963-67$ & 86 & 216 & 474 & 622 & 835 & 2233 & 16 & 55 & 117 & 181 & 244 & 613 \\
\hline 1968-72 & 6 & 113 & 270 & 409 & 489 & 1287 & 3 & 36 & 64 & 92 & 131 & 326 \\
\hline 1973-77 & & 11 & 89 & 254 & 341 & 695 & & 2 & 31 & 59 & 88 & 180 \\
\hline 1978-82 & & & 5 & 132 & 280 & 417 & & & 3 & 40 & 90 & 133 \\
\hline $1983-87$ & & & & 5 & 97 & 102 & & & & 7 & 62 & 69 \\
\hline
\end{tabular}

Denmark

Follow-up years

$\begin{array}{lrrrrrrrrrrrr}\text { Total } & 90515 & 46033 & 36595 & 39291 & 43803 & 256237 & 91650 & 48089 & 39826 & 44004 & 47647 & 271216 \\ 1918-22 & 4524 & 1692 & 1205 & 756 & 417 & 8594 & 7930 & 3643 & 2463 & 1989 & 1029 & 17054 \\ 1923-27 & 5675 & 2073 & 1340 & 919 & 564 & 10571 & 9059 & 3818 & 2562 & 2149 & 1475 & 19063 \\ 1928-32 & 7244 & 2628 & 1533 & 1084 & 738 & 13227 & 9416 & 3799 & 2395 & 1879 & 1362 & 18851 \\ 1933-37 & 8610 & 3296 & 1940 & 1312 & 1076 & 16234 & 10215 & 4361 & 2588 & 2002 & 1543 & 20709 \\ 1938-42 & 10544 & 4295 & 2505 & 1935 & 1649 & 20928 & 11155 & 4926 & 3203 & 2412 & 1891 & 23587 \\ 1943-47 & 14555 & 6243 & 3942 & 3215 & 2672 & 30627 & 13439 & 6466 & 4262 & 3600 & 2813 & 30580 \\ 1948-52 & 13700 & 6100 & 4050 & 3614 & 3244 & 30708 & 10480 & 5479 & 4128 & 3889 & 3253 & 27229\end{array}$


Table 1 The number of follow-up years and deaths by study period, birth cohort and sex in Denmark and Finland (Continued)

\begin{tabular}{|c|c|c|c|c|c|c|c|c|c|c|c|c|}
\hline 1953-57 & 11866 & 6013 & 4637 & 4241 & 3888 & 30645 & 8978 & 4777 & 4146 & 4018 & 3821 & 25740 \\
\hline $1958-62$ & 8456 & 5069 & 4363 & 4672 & 4822 & 27382 & 6338 & 4068 & 3779 & 4181 & 4284 & 22650 \\
\hline 1963-67 & 4729 & 5329 & 4314 & 5028 & 5738 & 25138 & 4015 & 3598 & 3567 & 4420 & 4827 & 20427 \\
\hline 1968-72 & 612 & 2811 & 3974 & 4281 & 5179 & 16857 & 625 & 2556 & 3126 & 4132 & 4876 & 15315 \\
\hline 1973-77 & & 484 & 2309 & 4697 & 5034 & 12524 & & 598 & 2869 & 4502 & 5039 & 13008 \\
\hline 1978-82 & & & 483 & 2936 & 5006 & 8425 & & & 738 & 3805 & 5648 & 10191 \\
\hline 1983-87 & & & & 601 & 3776 & 4377 & & & & 1026 & 5786 & 6812 \\
\hline \multicolumn{13}{|l|}{ Deaths } \\
\hline Total & 2856 & 1472 & 1242 & 1243 & 1192 & 8005 & 2132 & 1147 & 923 & 934 & 894 & 6030 \\
\hline 1918-22 & 425 & 187 & 181 & 147 & 96 & 1036 & 392 & 225 & 207 & 194 & 130 & 1148 \\
\hline 1923-27 & 370 & 217 & 139 & 136 & 106 & 968 & 365 & 200 & 160 & 179 & 127 & 1031 \\
\hline 1928-32 & 372 & 161 & 107 & 99 & 98 & 837 & 290 & 158 & 134 & 100 & 124 & 806 \\
\hline 1933-37 & 339 & 170 & 104 & 106 & 84 & 803 & 246 & 134 & 76 & 84 & 87 & 627 \\
\hline $1938-42$ & 305 & 154 & 121 & 108 & 109 & 797 & 232 & 128 & 85 & 67 & 83 & 595 \\
\hline $1943-47$ & 364 & 165 & 132 & 134 & 124 & 919 & 237 & 104 & 82 & 98 & 70 & 591 \\
\hline 1948-52 & 290 & 122 & 119 & 118 & 141 & 790 & 164 & 71 & 54 & 64 & 73 & 426 \\
\hline 1953-57 & 231 & 116 & 113 & 126 & 117 & 703 & 121 & 55 & 36 & 46 & 62 & 320 \\
\hline $1958-62$ & 127 & 71 & 79 & 85 & 88 & 450 & 62 & 36 & 37 & 41 & 55 & 231 \\
\hline $1963-67$ & 33 & 81 & 71 & 67 & 80 & 332 & 23 & 23 & 19 & 27 & 29 & 121 \\
\hline 1968-72 & 0 & 27 & 47 & 56 & 53 & 183 & 0 & 11 & 22 & 15 & 22 & 70 \\
\hline 1973-77 & & 1 & 27 & 34 & 52 & 114 & & 2 & 10 & 13 & 13 & 38 \\
\hline 1978-82 & & & 2 & 25 & 33 & 60 & & & 1 & 6 & 11 & 18 \\
\hline 1983-87 & & & & 2 & 11 & 13 & & & & 0 & 8 & 8 \\
\hline
\end{tabular}

retrieved from the Danish and Finnish national hospital registers. Patients with a diagnosis of intellectual disability (F70-79) at any point in time were excluded. Hospitalisations due to organic mental disorders, e.g. dementia, (F00-09) resulted in exclusion of the subject starting from the first hospitalisation due to dementia and any episode afterwards. Patients with a diagnosis related to intellectual disability and dementia were excluded because of the high risk for premature mortality inherent to the organic nature of these disorders.

\section{Information on deaths}

Information on deaths was taken from national cause-of-death registers, which cover all citizens and permanent residents, and linked to the hospital data with the unique personal identity code, which is given to all citizens at birth and permanent residents at migration.

\section{Data sources}

\section{Denmark}

The Danish Psychiatric Central Register [14] covers all psychiatric inpatient facilities in Denmark and has been computerised since 1969. In Denmark, the ICD-8 classification was used as the diagnostic system used until 1993 and the ICD-10 was introduced in 1994.

The Danish Cause of Death Register contains information about all deaths of Danish citizens and residents, date of death, and circumstances and causes of death. The register has a high level of completeness and its validity has been evaluated with very good results [15].

\section{Finland}

The Finnish Hospital Discharge Register (FHDR) includes data on all inpatient episodes on an individual level since 1969. For diagnosis, ICD-8 was used during the period 1969-1986, ICD-9 during the period 19871995 and ICD-10 from 1996 onwards. The FHDR has been found to be a valid and reliable tool for epidemiological research [16].

The Finnish Cause of Death Register records data on the deaths of all citizens and permanent residents in Finland. The register has a high level of completeness. All diagnoses of the causes of death have to pass a routine validation carried out by regional medical officers and physicians at Statistics Finland. Generally, the quality has been found to be very good [17]. 
Table 2 Mortality per 100000 among women with severe mental disorders requiring hospitalization by birth cohort in 1982-2006

\begin{tabular}{|c|c|c|c|c|c|c|c|c|c|c|c|c|c|}
\hline Men & & & & & & & & & & & & & \\
\hline \multicolumn{14}{|c|}{ Denmark } \\
\hline & $15-19$ & $20-24$ & $25-29$ & $30-34$ & $35-39$ & $40-44$ & $45-49$ & $50-54$ & $55-59$ & $60-64$ & $65-69$ & $70-74$ & $75-79$ \\
\hline 1918-22 & & & & & & & & & & 9394 & 11050 & 15023 & 19452 \\
\hline 1923-27 & & & & & & & & & 6520 & 10470 & 13706 & 14801 & 18793 \\
\hline 1928-32 & & & & & & & & 5136 & 6125 & 6981 & 9131 & 13275 & \\
\hline 1933-37 & & & & & & & 3937 & 5158 & 5361 & 8078 & 7806 & & \\
\hline $1938-42$ & & & & & & 2893 & 3586 & 4831 & 5582 & 6612 & & & \\
\hline $1943-47$ & & & & & 2501 & 2643 & 3349 & 4168 & 4641 & & & & \\
\hline 1948-52 & & & & 2117 & 2000 & 2938 & 3265 & 4346 & & & & & \\
\hline 1953-57 & & & 1947 & 1929 & 2437 & 2971 & 3009 & & & & & & \\
\hline $1958-62$ & & 1502 & 1401 & 1811 & 1819 & 1825 & & & & & & & \\
\hline 1963-67 & 698 & 1520 & 1646 & 1333 & 1394 & & & & & & & & \\
\hline 1968-72 & 961 & 1183 & 1308 & 1023 & & & & & & & & & \\
\hline 1973-77 & 1170 & 724 & 1033 & & & & & & & & & & \\
\hline 1978-82 & 852 & 659 & & & & & & & & & & & \\
\hline 1983-87 & 291 & & & & & & & & & & & & \\
\hline \multicolumn{14}{|l|}{ Finland } \\
\hline 1918-22 & & & & & & & & & & 6806 & 8790 & 11195 & 13385 \\
\hline $1923-27$ & & & & & & & & & 5493 & 6862 & 8351 & 9977 & 10973 \\
\hline 1928-32 & & & & & & & & 3817 & 5176 & 6062 & 6924 & 8407 & \\
\hline 1933-37 & & & & & & & 3107 & 3793 & 4101 & 4799 & 5659 & & \\
\hline $1938-42$ & & & & & & 2526 & 2989 & 3113 & 3789 & 4280 & & & \\
\hline 1943-47 & & & & & 2066 & 2478 & 2597 & 2970 & 3543 & & & & \\
\hline $1948-52$ & & & & 1653 & 2133 & 2190 & 2486 & 2922 & & & & & \\
\hline 1953-57 & & & 1436 & 1815 & 1722 & 1958 & 2138 & & & & & & \\
\hline 1958-62 & & 1081 & 1237 & 1278 & 1532 & 1686 & & & & & & & \\
\hline 1963-67 & 627 & 683 & 875 & 924 & 1069 & & & & & & & & \\
\hline 1968-72 & 758 & 588 & 700 & 721 & & & & & & & & & \\
\hline 1973-77 & 521 & 580 & 605 & & & & & & & & & & \\
\hline 1978-82 & 534 & 522 & & & & & & & & & & & \\
\hline 1983-87 & 459 & & & & & & & & & & & & \\
\hline \multicolumn{14}{|l|}{ Women } \\
\hline \multicolumn{14}{|c|}{ Denmark } \\
\hline & $15-19$ & $20-24$ & $25-29$ & $30-34$ & $35-39$ & $40-44$ & $45-49$ & $50-54$ & $55-59$ & $60-64$ & $65-69$ & $70-74$ & $75-79$ \\
\hline 1918-22 & & & & & & & & & & 4943 & 6176 & 8405 & 9756 \\
\hline 1923-27 & & & & & & & & & 4029 & 5239 & 6244 & 8329 & 8610 \\
\hline 1928-32 & & & & & & & & 3080 & 4159 & 5596 & 5323 & 9107 & \\
\hline 1933-37 & & & & & & & 2408 & 3073 & 2937 & 4197 & 5637 & & \\
\hline 1938-42 & & & & & & 2080 & 2599 & 2654 & 2778 & 4390 & & & \\
\hline $1943-47$ & & & & & 1764 & 1609 & 1924 & 2722 & 2489 & & & & \\
\hline 1948-52 & & & & 1565 & 1296 & 1308 & 1646 & 2244 & & & & & \\
\hline 1953-57 & & & 1348 & 1151 & 868 & 1145 & 1622 & & & & & & \\
\hline
\end{tabular}


Table 2 Mortality per 100000 among women with severe mental disorders requiring hospitalization by birth cohort in 1982-2006 (Continued)

\begin{tabular}{|c|c|c|c|c|c|c|c|c|c|c|c|c|c|}
\hline $1958-62$ & & 978 & 885 & 979 & 981 & 1284 & & & & & & & \\
\hline $1963-67$ & 573 & 639 & 533 & 611 & 601 & & & & & & & & \\
\hline 1968-72 & 430 & 704 & 363 & 451 & & & & & & & & & \\
\hline $1973-77$ & 349 & 289 & 258 & & & & & & & & & & \\
\hline 1978-82 & 158 & 195 & & & & & & & & & & & \\
\hline 1983-87 & 138 & & & & & & & & & & & & \\
\hline \multicolumn{14}{|l|}{ Finland } \\
\hline $1918-22$ & & & & & & & & & & 3354 & 4942 & 6457 & 8372 \\
\hline $1923-27$ & & & & & & & & & 2738 & 3345 & 3968 & 5366 & 6463 \\
\hline 1928-32 & & & & & & & & 1826 & 2356 & 2515 & 3110 & 4164 & \\
\hline 1933-37 & & & & & & & 1404 & 1523 & 1724 & 2359 & 2592 & & \\
\hline 1938-42 & & & & & & 1198 & 1467 & 1358 & 1657 & 1928 & & & \\
\hline $1943-47$ & & & & & 1025 & 1015 & 1099 & 1265 & 1563 & & & & \\
\hline $1948-52$ & & & & 741 & 962 & 919 & 1097 & 1234 & & & & & \\
\hline 1953-57 & & & 855 & 721 & 791 & 922 & 1046 & & & & & & \\
\hline $1958-62$ & & 782 & 543 & 653 & 629 & 753 & & & & & & & \\
\hline $1963-67$ & 275 & 465 & 478 & 504 & 522 & & & & & & & & \\
\hline $1968-72$ & 564 & 389 & 352 & 365 & & & & & & & & & \\
\hline 1973-77 & 344 & 304 & 298 & & & & & & & & & & \\
\hline 1978-82 & 271 & 308 & & & & & & & & & & & \\
\hline $1983-87$ & 258 & & & & & & & & & & & & \\
\hline
\end{tabular}

\section{Statistical analysis}

The population at risk consisted of all patients admitted at least once during the period 1 January 1982 and 31 December 2006. Mortality follow-up was based on death during the same period. The mortality rates were studied separately for men and women for five-year birth cohorts born in 1918-1922 until 1983-1987 and for death year groups, grouped in five year periods as follows: 1982-1986, 1987-1991, 1992-1996, 1997-2001 and 2002-2006. Basic information on the number of cases and deaths are presented in Table 1.

Comparisons were made for total mortality rate for the whole population for the same birth cohorts and for both sexes. Observed/expected ratios (O/E ratios) with 95\% confidence intervals were calculated for each mortality rate comparison. Expected mortality rates were based on mortality rates among total population provided by sex and five-year age groups by the national statistical offices. The mortality differences between birth cohorts were calculated by using the test for relative proportions. The statistical analysis was made by using SAS version 9.3.

\section{Results}

Overall mortality, measured as total number of deaths per 100,000 years of follow-up, among patients with severe mental disorders declined for each cohort in both countries (Table 2, Figure 2). For Danish men aged 1534 years old and women aged 15-39 years old as well as for Finnish men and women aged 20-34 years old, the mortality rates more than halved during the study period. The smallest decline was observed for Finnish men aged $15-19$ years old $(-27 \%)$ and $50-54$ years old $(-23 \%)$ as well as for Danish men aged $45-59$ years old $(-24 \%,-15 \%$ and $-29 \%$ in each five-year age group, respectively). For women, the smallest decline was observed in Finland in age group 15-19 years old (-6\%), and in Denmark in age groups $45-54$ years old $(-26 \%$ and $-27 \%$ in the two five-year age groups, respectively).

In both countries and in all cohorts, patient with severe mental disorders had a higher mortality than general population (Table 3 for men and Table 4 for women). Generally, the excess mortality was higher in Denmark than in Finland. Among Danish men aged 1564 years old, the mean excess mortality was 9 -fold in 1982-86, but declined to 7-fold in 2002-2006 compared to general population $(\mathrm{p}<0.001)$. For Finnish men, the excess mortality remained between 4- and 5-fold during the whole study period. For women in the same age groups, the mean excess mortality declined in both countries. The relative improvement was larger for Danish women (from 12-fold in 1982-86 to 6-fold 
a) men in Denmark

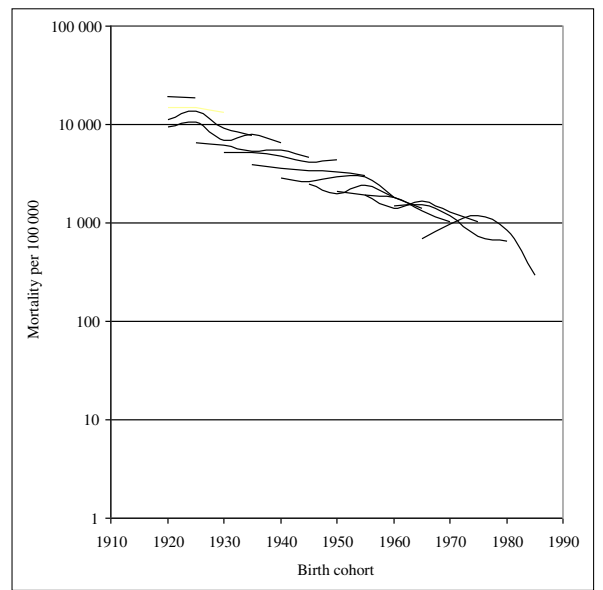

c) women in Denmark

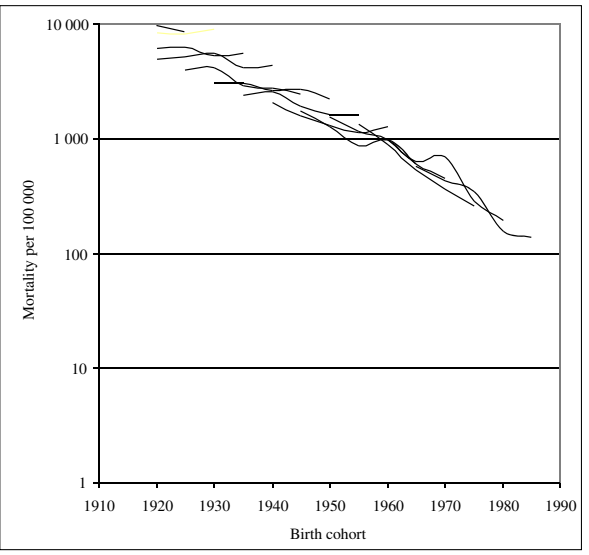

b) men in Finland

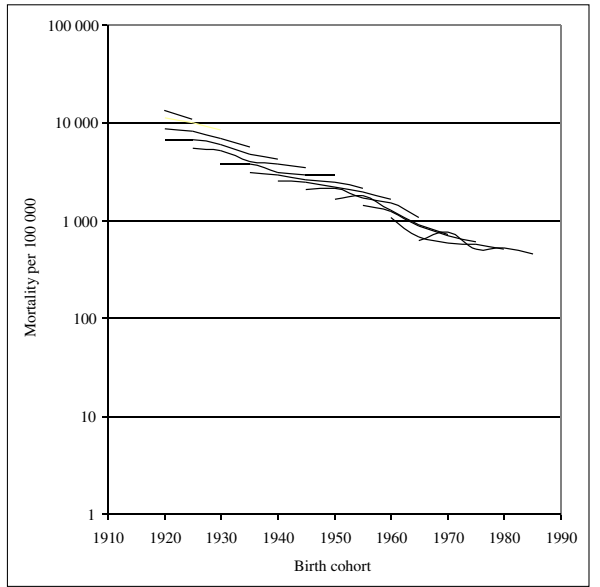

d) women in Finland

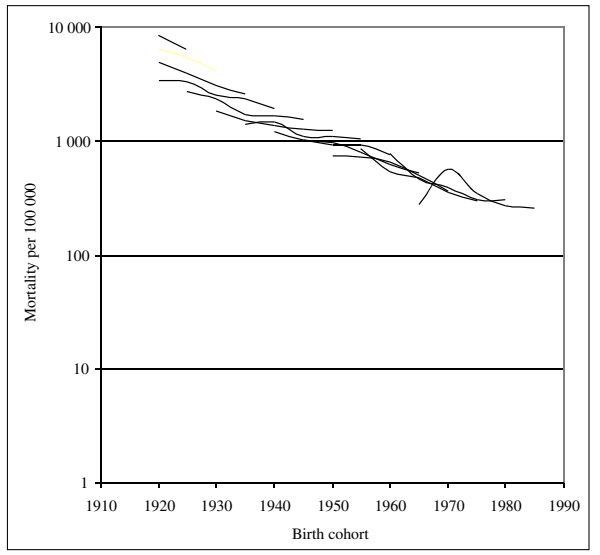

Figure 2 Mortality with severe mental disorder by birth cohort in 1982-2006, logarithmic scale a) men in Denmark, b) men in Finland, c) women in Denmark, d) women in Finland. Each line represents an age group through the follow-up period of up to 25 years.

mortality in 2002-06, $\mathrm{p}<0.001$ ) than for Finnish women (from 9-fold to 6-fold, $\mathrm{p}<0.001$ ). By age groups, the excess mortality declined most for Danish men and women aged 15-49 years old as well as for Finnish men aged 25-39 years old and Finnish women aged 20-59 years old.

Two exceptions were observed when investigating mortality by birth cohorts. First, the excess mortality risk stagnated among Finnish men born in 1963-1987, and remained more than five-fold compared to general population at ages 15-24 years. In both countries, the mortality among male patients with severe mental disorders decreased, when comparing men born 1963-72 and 1978-87 $(<0.001)$, but the decline was more substantial in Denmark $(-43 \%)$ compared to Finland $(-23 \%)$. The excess mortality declined in Denmark from being 11.9fold (95\% confidence interval 10.0-14.0) for men born 1963-72 to 8.7-fold (7.1-10.5) for men born 1978-87, while no progress was observed in Finland: the excess risks for mortality among patients with severe mental disorders were 5.2-fold (4.7-5.8) for Finnish men born 1978-82 and 5.3-fold (4.9-5.7) for Finnish men born 1983-87.

Second, the excess mortality risk stagnated for Danish and Finnish women born in 1933-1957 at their 40s. Their mortality remained six-fold in Denmark and Finland at ages 45-49 years and seven-fold in Denmark at ages 40-44 years. Between cohorts 1933-37 and 1953-57, the mortality at 40-44 years and 45-49 years declined both in Denmark (-33\%, p $=0.002$ and $-27 \%$, $\mathrm{p}<0.001)$ and in Finland $(-26 \%, \mathrm{p}<0.001$ and $-19 \%$, $\mathrm{p}<0.001)$, but the excess mortality remained at the same level. In Denmark, it was for women aged 40-44 years old 6.3-fold (95\% confidence interval 6.1-6.5) for women born 1933-37 and 5.9-fold (5.5-6.3) for women born 1953-57. For women aged 45-49 years old the excess risks were 5.1-fold (4.9-5.4) and 5.2-fold (4.9-5.5), respectively. For Finland, the excess mortality decreased for women aged 40-44 years old from 5.8-fold (5.6-6.0) for women born 1933-37 to 4.7-fold (4.5-4.9) for 
Table 3 Excess mortality calculated as observed/expected ratio with $95 \%$ confidence intervals among male patients with mental disorders compared with general population, by birth cohort, Denmark and Finland 1982-2006

\begin{tabular}{|c|c|c|c|c|c|}
\hline & $1982-86$ & $1987-91$ & 1992-96 & 1997-01 & $2002-06$ \\
\hline \multicolumn{6}{|l|}{ Denmark } \\
\hline 1918-22 & $3.8(3.2-4.6)$ & $3.0(2.6-3.4)$ & $2.7(2.4-3.0)$ & $2.4(2.2-2.7)$ & $2.0(1.8-2.2)$ \\
\hline $1923-27$ & $6.8(6.3-7.4)$ & $7.2(5.4-9.4)$ & $6.2(5.0-7.5)$ & $4.7(4.0-5.5)$ & $4.3(3.8-4.8)$ \\
\hline 1928-32 & $5.4(4.8-6.0)$ & $4.2(2.7-5.7)$ & $3.1(2.5-3.8)$ & $2.9(2.7-3.0)$ & $3.0(2.6-3.5)$ \\
\hline 1933-37 & $6.9(6.3-7.6)$ & $5.7(4.5-6.9)$ & $4.0(3.9-4.2)$ & $4.3(4.1-4.4)$ & $3.0(2.6-3.4)$ \\
\hline $1938-42$ & $8.9(8.1-9.7)$ & $7.0(6.1-7.9)$ & $6.3(6.1-6.4)$ & $4.9(4.7-5.2)$ & $4.1(3.8-4.4)$ \\
\hline $1943-47$ & $11.8(10.8-12.9)$ & $8.0(7.4-8.5)$ & $6.9(6.5-7.2)$ & $5.9(5.6-6.2)$ & $4.5(4.4-4.7)$ \\
\hline 1948-52 & $12.5(11.4-13.7)$ & $8.9(8.3-9.5)$ & $9.0(8.5-9.5)$ & $7.1(6.7-7.5)$ & $6.4(6.1-6.8)$ \\
\hline 1953-57 & $15.2(13.6-16.9)$ & $11.8(10.9-12.7)$ & $10.2(9.6-10.9)$ & $9.7(9.2-10.2)$ & $6.7(6.2-7.2)$ \\
\hline $1958-62$ & $13.5(11.7-15.5)$ & $11.5(10.3-12.8)$ & $11.8(10.9-12.8)$ & $10.0(9.3-10.7)$ & $6.9(6.3-7.4)$ \\
\hline $1963-67$ & $8.2(6.5-10.1)$ & $14.3(12.5-16.3)$ & $14.9(13.5-16.3)$ & $10.8(10.0-11.6)$ & $8.6(8.1-9.2)$ \\
\hline 1968-72 & & $12.7(10.5-15.3)$ & $13.7(12.1-15.5)$ & $14.1(12.8-15.5)$ & $9.6(8.8-10.5)$ \\
\hline 1973-77 & & & $16.6(13.3-20.4)$ & $10.1(8.9-11.4)$ & $12.4(11.1-13.8)$ \\
\hline 1978-82 & & & & $12.0(10.1-14.3)$ & $8.6(7.6-9.7)$ \\
\hline 1983-87 & & & & & $4.3(3.5-5.2)$ \\
\hline \multicolumn{6}{|l|}{ Finland } \\
\hline 1918-22 & $1.2(1.1-1.3)$ & $2.2(2.0-2.5)$ & $2.0(1.9-2.2)$ & $1.7(1.6-1.8)$ & $1.4(1.3-1.5)$ \\
\hline 1923-27 & $3.6(3.3-3.9)$ & $4.3(3.4-5.4)$ & $3.9(3.3-4.5)$ & $3.4(3.0-3.8)$ & $2.7(2.5-3.0)$ \\
\hline 1928-32 & $2.5(2.2-2.7)$ & $3.3(2.5-4.0)$ & $2.8(2.3-3.3)$ & $2.4(2.3-2.5)$ & $2.1(1.9-2.3)$ \\
\hline 1933-37 & $2.6(2.4-2.9)$ & $3.9(3.3-4.6)$ & $3.2(2.8-3.6)$ & $2.7(2.6-2.9)$ & $2.4(2.1-2.6)$ \\
\hline 1938-42 & $4.0(3.7-4.4)$ & $4.7(4.1-5.2)$ & $3.7(3.4-4.1)$ & $3.3(3.1-3.5)$ & $2.7(2.6-2.9)$ \\
\hline 1943-47 & $5.9(5.4-6.4)$ & $5.7(5.3-6.1)$ & $4.6(4.4-4.9)$ & $3.8(3.7-4.0)$ & $3.3(3.2-3.4)$ \\
\hline 1948-52 & $6.3(5.7-6.9)$ & $6.7(6.2-7.2)$ & $5.2(4.9-5.6)$ & $4.7(4.4-4.9)$ & $3.9(3.6-4.1)$ \\
\hline 1953-57 & $6.1(5.5-6.8)$ & $8.0(7.4-8.6)$ & $6.3(5.8-6.7)$ & $5.4(5.1-5.7)$ & $4.3(4.0-4.6)$ \\
\hline $1958-62$ & $6.2(5.4-7.1)$ & $7.6(6.8-8.5)$ & $7.2(6.6-7.8)$ & $6.6(6.2-7.0)$ & $5.3(5.0-5.6)$ \\
\hline 1963-67 & $4.8(3.9-5.9)$ & $5.0(4.4-5.8)$ & $6.1(5.5-6.7)$ & $6.0(5.6-6.5)$ & $5.4(5.0-5.8)$ \\
\hline 1968-72 & & $6.0(5.0-7.3)$ & $5.0(4.5-5.7)$ & $5.5(5.0-6.1)$ & $5.4(4.9-5.9)$ \\
\hline 1973-77 & & & $5.4(4.4-6.7)$ & $5.3(4.7-6.0)$ & $5.5(5.0-6.2)$ \\
\hline 1978-82 & & & & $6.0(5.0-7.1)$ & $5.0(4.4-5.6)$ \\
\hline 1983-87 & & & & & $5.5(4.4-6.7)$ \\
\hline
\end{tabular}

women born 1953-57, but the difference remains statistically insignificant for women aged $45-49$ years with a change from being 4.2-fold (4.0-4.4) to being 3.8-fold (3.6-4.0).

\section{Discussion}

Our data confirmed the declining mortality trends among hospitalised patients with severe mental disorders in Denmark and Finland. In general, the mortality gap diminished for each consecutive birth cohort, but patients with mental disorders still had a significantly higher mortality rate than the total population in general.

We observed that the relative mortality among young Finnish men born in 1963-1987 with severe mental disorders leading to hospitalisation did not improve at all.
One explanation may be the Finnish recession in the early 1990s, which seems to have affected these birth cohorts most. At the time of the recession in Finland, these boys and young men were affected by adversities in their families of origin [18] and faced considerable problems in accessing the labour market [19].

The sex-specific effect may be explained by socioeconomic disparities, which significantly differ between men and women. The educational level of Finnish young men is lower than among young women. In 2009, 23\% of men aged $25-29$ years old and $34 \%$ of men aged $30-$ 34 years old had a tertiary education, while the percentages were substantially higher $(40 \%$ and $53 \%$, respectively) for women in the same age groups [20]. Also the unemployment figures have been higher for men aged 
Table 4 Excess mortality calculated as observed/expected ratio with $95 \%$ confidence intervals among female patients with mental disorders compared with general population, by birth cohort, Denmark and Finland 1982-2006

\begin{tabular}{|c|c|c|c|c|c|}
\hline & $1982-86$ & 1987-91 & $1992-96$ & 1997-01 & 2002-06 \\
\hline \multicolumn{6}{|l|}{ Denmark } \\
\hline 1918-22 & $3.7(3.0-4.6)$ & $3.0(2.6-3.5)$ & $2.6(2.4-2.7)$ & $2.0(1.8-2.1)$ & $1.6(1.5-1.7)$ \\
\hline 1923-27 & $6.5(5.8-7.3)$ & $5.6(2.6-9.9)$ & $4.4(3.2-5.9)$ & $4.0(3.1-5.0)$ & $2.9(2.4-3.5)$ \\
\hline 1928-32 & $5.0(4.4-5.7)$ & $4.5(4.0-5.0)$ & $4.0(3.6-4.3)$ & $2.5(1.8-3.2)$ & $3.1(2.7-3.5)$ \\
\hline 1933-37 & $6.3(5.4-7.4)$ & $5.1(4.5-5.8)$ & $3.3(3.0-3.7)$ & $3.2(2.7-3.8)$ & $3.2(3.0-3.4)$ \\
\hline 1938-42 & $9.2(7.7-10.8)$ & $7.3(6.4-8.2)$ & $5.1(4.6-5.6)$ & $3.7(3.4-4.0)$ & $4.3(4.0-4.7)$ \\
\hline 1943-47 & $13.1(11.1-15.3)$ & $7.5(6.6-8.5)$ & $5.8(5.3-6.4)$ & $5.8(5.4-6.3)$ & $3.7(3.2-4.3)$ \\
\hline 1948-52 & $18.0(15.0-21.6)$ & $10.3(9.0-11.6)$ & $6.1(5.5-6.8)$ & $5.5(5.0-5.9)$ & $5.2(4.7-5.7)$ \\
\hline 1953-57 & $23.9(19.8-28.7)$ & $14.8(12.6-17.3)$ & $6.7(6.0-7.5)$ & $6.2(5.6-6.7)$ & $5.9(5.5-6.4)$ \\
\hline $1958-62$ & $24.4(18.9-30.9)$ & $17.3(13.7-21.5)$ & $13.3(11.5-15.3)$ & $9.0(7.9-10.1)$ & $8.3(7.5-9.1)$ \\
\hline 1963-67 & $18.2(10.4-29.5)$ & $17.9(13.5-23.4)$ & $12.6(10.4-15.1)$ & $9.8(8.4-11.4)$ & $6.7(5.9-7.6)$ \\
\hline 1968-72 & & $14.7(10.3-20.3)$ & $22.9(17.6-29.3)$ & $9.4(7.6-11.5)$ & $8.8(7.4-10.4)$ \\
\hline 1973-77 & & & $12.2(8.3-17.3)$ & $10.4(7.9-13.4)$ & $8.1(6.5-10.0)$ \\
\hline 1978-82 & & & & $6.8(4.9-9.3)$ & $7.1(5.7-8.8)$ \\
\hline 1983-87 & & & & & $6.3(4.8-8.0)$ \\
\hline \multicolumn{6}{|l|}{ Finland } \\
\hline 1918-22 & $2.1(1.8-2.5)$ & $2.8(2.5-3.3)$ & $2.3(2.1-2.5)$ & $1.8(1.6-2.0)$ & $1.3(1.1-1.5)$ \\
\hline $1923-27$ & $6.6(5.8-7.4)$ & $5.8(3.1-9.2)$ & $4.8(3.4-6.5)$ & $4.3(3.4-5.4)$ & $3.3(2.8-3.9)$ \\
\hline 1928-32 & $4.4(3.8-5.0)$ & $4.1(3.7-4.5)$ & $3.0(2.8-3.3)$ & $2.5(1.7-3.3)$ & $2.2(1.8-2.5)$ \\
\hline 1933-37 & $5.8(4.9-6.7)$ & $4.2(3.7-4.7)$ & $3.4(3.1-3.8)$ & $3.2(2.6-3.8)$ & $2.5(2.3-2.6)$ \\
\hline 1938-42 & $6.9(5.8-8.1)$ & $5.7(5.0-6.4)$ & $4.0(3.6-4.4)$ & $3.6(3.3-3.9)$ & $2.9(2.6-3.1)$ \\
\hline 1943-47 & $11.3(9.6-13.2)$ & $6.5(5.7-7.4)$ & $4.7(4.3-5.2)$ & $3.9(3.6-4.2)$ & $3.4(3.0-3.7)$ \\
\hline $1948-52$ & 11.4 (9.4-13.6) & $8.5(7.5-9.7)$ & $5.9(5.3-6.5)$ & $4.6(4.3-5.0)$ & $3.8(3.4-4.1)$ \\
\hline 1953-57 & $17.2(14.2-20.6)$ & $10.0(8.5-11.7)$ & $7.7(6.8-8.6)$ & $6.1(5.6-6.7)$ & $4.7(4.3-5.0)$ \\
\hline 1958-62 & $22.0(17.1-27.9)$ & $11.6(9.2-14.4)$ & $10.0(8.6-11.5)$ & $6.7(5.9-7.6)$ & $5.3(4.8-5.9)$ \\
\hline 1963-67 & $8.2(4.7-13.3)$ & $12.0(9.0-15.6)$ & $10.5(8.7-12.6)$ & $7.8(6.7-9.0)$ & $6.5(5.7-7.4)$ \\
\hline 1968-72 & & $13.9(9.8-19.3)$ & $10.8(8.3-13.8)$ & $8.9(7.2-10.9)$ & $6.6(5.5-7.8)$ \\
\hline 1973-77 & & & $11.5(7.8-16.3)$ & $8.7(6.7-11.3)$ & $8.5(6.8-10.5)$ \\
\hline 1978-82 & & & & $8.7(6.2-11.8)$ & $9.2(7.4-11.3)$ \\
\hline 1983-87 & & & & & $8.9(6.8-11.4)$ \\
\hline
\end{tabular}

less than 25 years old. This suggests that the likelihood to be excluded or underprivileged has remained high among young Finnish men during the 1990s recession and after it.

Also women with severe mental disorders born before, during or after World War II, in the period 1933-1957, failed to reduce their excess mortality. This may reflect a generation of women with severe mental disorders who initially were extensively hospitalised due to their mental disorder, and were too old to benefit from the deinstitutionalised psychiatry which began to evolve in the 1970s. During the era of high level of psychiatric hospitalisation, people with mental disorders that nowadays are treated in community care were exposed to extensive hospitalisation periods, which resulted in iatrogenic adverse effects on level of functioning. It is possible that our findings illustrate a "lost generation", i.e. a generation with excess mortality due to excess hospitalisation. Previous reports have indicated an excess mortality among in-patient psychiatric populations $[21,22]$.

\section{Limitations}

Our study data covered all institutionalised people with mental disorders in Denmark and Finland during 25 years. The data collection systems are obligatory and their quality for register-based research has been shown to be good $[14,16]$. Also, the same exclusion and inclusion criteria were applied for both countries. The register-based data have, however, its limitations. 
There may be differences in the provision of health services, especially in the use of inpatient care services between the two study countries. The proportion of untreated or inappropriately treated people with severe mental disorder may differ in the two study countries and also during the study period. The distribution of diagnoses is different, since Denmark has reported more depression and drug-related treatments, while schizophrenia and alcohol-related treatments were more common in Finland [23]. Epidemiological studies confirm that schizophrenia spectrum disorders [24] and alcohol use disorders [25] may be more common in Finland than in other countries. Furthermore, our analyses do not allow complete comparisons between cohorts. For the older ones, the people with most serious mental disorders have already died, and thus they are excluded from our data.

The data was based on admission data, but the cohort definition was based on primary diagnoses at discharge, which is more accurate measure for patient with mental disorders than the admission diagnoses. Our data did not cover all psychiatric diagnoses. People with intellectual disabilities were excluded. The patients were also excluded from the date they received a diagnoses related to organic mental disorder, such as dementia. Both of these patient groups have high risk for premature mortality. Furthermore, we could not compare the distribution of mental disorders by year cohort due to differences in the register data in Denmark and Finland. Such differences by age group are well-known, but we cannot say, if these varied between the two study countries.

Our study data did not include information on international migration. Thus people who have permanently migrated abroad are included in the population at risk even though they may have died after leaving the country where they were treated. Since the migration rates are relatively low in the Nordic countries, we can estimate that the effect of not having information on migration is minor.

Due to the long follow-up period we were not able to get detailed background information on the people with severe mental disorders. The register-based information systems based on personal identification numbers in Denmark and Finland have been built from the 1970s onwards, and the information available before that is very limited. Therefore, we had to limit our analyses to basic variables available in the data sources, and thus, our conclusions remain partly speculative.

\section{Conclusions}

Although our data indicate that for each birth cohort the mortality gap between people with mental disorders is decreasing, our results also indicate that the favourable overall trend in this vulnerable population can easily be offset by selective disadvantages. Two major societal changes, i.e. the deep Finnish recession in the 1990s and the excessive long-term hospitalisation of people with mental disorders in the 1950s to 1970s, may have contributed to lack of progress in equity in terms of mortality in groups who were particularly exposed to these major societal changes.

Besides accessible and responsive primary health care, active labour market policy, social welfare policies supporting families and parenting and programmes to support unmanageable dept should be used to diminish mental and somatic health problems during economic downturn and recession [26]. If the economic crisis continues for a longer time, it is important to fight against poverty and its inheritance, since mental health problems effect also families. [27].

\section{Competing interests}

The authors have no competing interest to report.

\section{Authors' contributions}

MG, TML, MN and KW planned the study. MG and TML made the analyses. MG wrote the article with contributions from all other authors (TML, UÖ, MN and $\mathrm{KW}$ ). All authors read and approved the final manuscript.

\section{Acknowledgements}

The permission to use health register data in scientific research was given by the data administering authorities. The data protection authorities in Denmark and Finland were informed on the study, as required by the national legislations on data protection. Neither ethical committee statement nor informed consents of the registered people were required.

This study was supported by a grant from the Nordic Council of Ministers.

\section{Author details}

${ }^{1}$ Nordic Research Academy in Mental Health, Nordic School of Public Health, Gothenburg, Sweden. ${ }^{2}$ THL National Institute for Health and Welfare, Helsinki, Finland. ${ }^{3}$ National Centre for Register-based Research, Aarhus University, Aarhus, Denmark. ${ }^{4}$ Department of Psychiatry, Tiohundra AB, Norrtälje, Sweden. ${ }^{5}$ Department of Molecular Medicine and Surgery, Karolinska Institutet, Stockholm, Sweden. ${ }^{6}$ Psychiatric Centre Bispebjerg, Copenhagen University, Faculty of Health Sciences, Copenhagen, Denmark.

Received: 27 March 2013 Accepted: 5 September 2013

Published: 11 September 2013

\section{References}

1. WHO Regional Office for Europe: European health for all database (HFA-DB). Copenhagen; 2011. Available at: www.euro.who.int/hfa. As accessed in 1 September 2012

2. Westman J, Gissler M, Wahlbeck K: Successful deinstitutionalisation of mental health care: life expectancy among people with mental disorders in Finland. Eur J Public Health 2012, 22(4):604-606.

3. Wahlbeck K, Westman J, Nordentoft M, Gissler M, Laursen TM: Outcomes of Nordic mental health systems: life expectancy of patients with mental disorders in Denmark, Finland and Sweden 1987-2006. Br J Psychiatry 2011, 199(6):453-458.

4. Laursen TM, Munk-Olsen T, Nordentoft M, Mortensen PB: Increased mortality among patients admitted with major psychiatric disorders: a register-based study comparing mortality in unipolar depressive disorder, bipolar affective disorder, schizoaffective disorder, and schizophrenia. J Clin Psychiatry 2007, 68(6):899-907.

5. Laursen TM, Munk-Olsen T, Agerbo E, Gasse C, Mortensen PB: Somatic hospital contacts, invasive cardiac procedures, and mortality from heart disease in patients with severe mental disorder. Arch Gen Psychiatry 2009, 66(7):713-720 
6. Laursen TM, Nordentoft M, Gissler M, Westman J, Wahlbeck K: Psykiatrisk registerforskning i Norden. En beskrivelse af forskningsmuligheder i psykiatrirelevante registre i Danmark, Sverige og Finland 2010 (in Scandinavian languages: psychiatric register-based research in the Nordic countries. A description of research possibilities in psychiatric-relevant registers in Denmark, Sweden and Finland 2010), NHV report 11. 2010. Available at: www.nhv.se/ upload/dokument/forskning/Publikationer/NHV-Rapport/Rapport_2010_ 11R_Psykiatrisk_registerforskning_i_Norden_nov_2010.pdf. As accessed 1 September 2012

7. Mäki N, Martikainen P: The role of socioeconomic indicators on nonalcohol and alcohol-associated suicide mortality among women in Finland. A register-based follow-up study of 12 million person-years. Soc Sci Med 2009, 68(12):2161-2169.

8. Rugulies R, Madsen IE, Nielsen MB, Olsen LR, Mortensen EL, Bech P: Occupational position and its relation to mental distress in a random sample of Danish residents. Int Arch Occup Environ Health 2010, 83(6):625-629.

9. Schiess MS, Christensen AB: Forekomsten af svær overvægt blandt psykiatriske patienter i Vejle Amt i 2002 (in Danish: incidence of severe obesity among psychiatric patients in the county of Vejle, Denmark, 2002). Ugeskr Laeger 2006, 168(42):3619-3622.

10. Räsänen S, Meyer-Rochow VB, Moring J, Hakko H: Hospital-treated physical illnesses and mortality: an 11-year follow-up study of long-stay psychiatric patients. Eur Psychiatry 2007, 22(4):211-218.

11. Druss BG, Bradford WD, Rosenheck RA, Radford MJ, Krumholz HM: Quality of medical care and excess mortality in older patients with mental disorders. Arch Gen Psychiatry 2001, 58:565-572.

12. Catalano R, Goldman-Mellor S, Saxton K, Margerison-Zilko C, Subbaraman M, LeWinn K, Anderson E: The health effects of economic decline. Annu Rev Public Health 2011, 32:431-450.

13. Stuckler D, Basu S, Suhrcke M, Coutts A, McKee M: The public health effect of economic crises and alternative policy responses in Europe: an empirical analysis. Lancet 2009, 374:315-323.

14. Mors O, Perto GP, Mortensen PB: The Danish psychiatric central research register. Scand J Public Health 2011, 39:54.

15. Helweg-Larsen K: The Danish registers of causes of death. Scand J Public Health 2011, 39:26.

16. Keskimäki I, Aro S: The accuracy of data on diagnoses, procedures and accidents in the Finnish hospital discharge register. Int J Health Serv 1991, 2:15-21.

17. Statistics Finland: Quality description of cause of death statistics. www tilastokeskus.fi/til/ksyyt/2007/ksyyt_2007_2008-11-07_laa_001_en.html. As accessed 1 September 2012.

18. Solantaus T, Leinonen J, Punamäki R-L: Children's mental health in times of economic recession: replication and extension of the family economic stress model in Finland. Develop Psychol 2004, 40(3):412-429.

19. Kalela J, Kiander J, Kivikuru U, Loikkanen HA, Simpura J: Down from the heavens, up from the ashes. The Finnish economic crisis in the light of economic and social research. Helsinki: VATT Publications 27:5; 2001.

20. Statistics Finland: Educational structure of population 2009. www. tilastokeskus.fi/til/vkour/index_en.html. As accessed 1 September 2012

21. Hewer W, Rössler W, Fatkenheuer B, Löffler W: Mortality among patients in psychiatric hospitals in Germany. Acta Psychiatr Scand 1995, 91:174-179.

22. Räsänen S, Hakko H, Viilo K, Meyer-Rochow VB, Moring J: Excess mortality among long-stay psychiatric patients in northern Finland. Soc Psychiatry Psychiatr Epidemiol 2003, 38:297-304.

23. Tuori T, Gissler M, Wahlbeck K, the Nordic reference group: Mental health in the Nordic countries, Health statistics in the Nordic countries 2005. Copenhagen: NOMESCO (Nordic Medico-Statistical Committee 80; 2007:149-211. A longer version available at: nomesco-da.nom-nos.dk/filer/ publikationer/Helse\%202005.pdf. As accessed 1 September 2012.

24. Perälä J, Suvisaari J, Saarni SI, Kuoppasalmi K, Isometsä E, Pirkola S, Partonen T, Tuulio-Henriksson A, Hintikka J, Kieseppä T, Härkänen T, Koskinen S, Lönnqvist J: Lifetime prevalence of psychotic and bipolar I disorders in a general population. Arch Gen Psychiatr 2007, 64:19-28.

25. Rehm J, Room R, van den Brinke W, Jacobi F: Alcohol use disorders in EU countries and Norway: an overview of the epidemiology. Eur Neuropsychopharmacology 2005, 15:377-388.
26. Wahlbeck K, McDaid D: Actions to alleviate the mental health impact of the economic crises. World Psychiatr 2012, 11:139-145.

27. Paananen R, Santalahti P, Merikukka N, Rämö A, Wahlbeck K, Gissler M: Socioeconomic and regional aspects in the use of specialised psychiatric care - a Finnish nationwide follow-up study. Eur J Public Health 2013, 23:372-377.

doi:10.1186/1471-2458-13-834

Cite this article as: Gissler et al:: Patterns in mortality among people with severe mental disorders across birth cohorts: a register-based study of Denmark and Finland in 1982-2006. BMC Public Health 2013 13:834.

\section{Submit your next manuscript to BioMed Central and take full advantage of:}

- Convenient online submission

- Thorough peer review

- No space constraints or color figure charges

- Immediate publication on acceptance

- Inclusion in PubMed, CAS, Scopus and Google Scholar

- Research which is freely available for redistribution 